\title{
Carbonatite formed through diamond oxidation
}

\author{
Wei-Dong Sun ${ }^{1,2,3}$, Li-peng Zhang ${ }^{1,2,3}$, Guo-zhi Xie ${ }^{1,2,3}$, \\ Chris Hawkesworth ${ }^{4}$ and Robert Zartmam ${ }^{1}$ \\ ${ }^{1}$ Center of Deep Sea Research, Institute of Oceanology, \\ Chinese Academy of Sciences, Qingdao 266071, P. R. \\ China (*Correspondence: weidongsun@qdio.ac.cn) \\ ${ }^{2}$ Qingdao National Laboratory for Marine Science and \\ Technology, Qingdao 266237, P. R. China \\ ${ }^{3}$ Center for Ocean Mega-Science, Chinese Academy of \\ Sciences, Qingdao 266071, P. R. China \\ ${ }^{4}$ Department of Earth \& Environmental Sciences, University \\ of St Andrews, North Street, St Andrews KY16 9AL, UK
}

Carbonatite is a magmatic rock with high carbonate and low silicate contents, which mostly originate in the mantle. It is therefore of critical importance to understand the behavior of carbon in the mantle, and consequently deep carbon recycling. However, the formation of carbonatite is largely unresolved. In particular, the source of earbonatite the carbonate remains obscure. Previous studies showed that the solidus of carbonated mantle peridotite was lower than the Earth's geotherm in the Archean and the Early Proterozoic era, before $\sim 1.4 \mathrm{Ga}$ ago. Therefore, the mantle should have been severely decarbonated early in Earth's history. This is consistent with the low carbon abundance in the asthenospheric mantle $(\sim 100 \mathrm{ppm})$, as indicated by low carbonate concentrations in mid-ocean ridge basalts. Consequently, carbonate in young mantle must have been mostly obtained in the post-Archean era by two processes. These are either oxidation of diamond in the mantle or recycling of sedimentary carbonates through plate subduction. Here we show that the $\mathrm{Sr}$ and $\mathrm{Nd}$ isotope variations in carbonatite may be plausibly explained by mixing of three endmembers, (1) recycled sedimentary carbonates, (2) depleted mantle, and (3) a low $\mathrm{Sr}$ and $\mathrm{Nd}$ isotopes endmember. The low $\mathrm{Sr}, \mathrm{Nd}$ carbonate reservoirs for carbonatites of different ages plot roughly on the evolution line of the primitive mantle, suggesting that they were successively released from a well-preserved, non-carbonate mantle source. The preferred candidate for this endmember is carbonate formed through oxidation of diamond by ferric ion released through decomposition of bridgmanite, which is carried up from the lower mantle via background upwelling, compensational to the volume of oceanic slabs penetrating into the lower mantle ${ }^{1}$.

1 Sun, W.-d., et al. 2018. Chemical Geology 478, 69-75. 